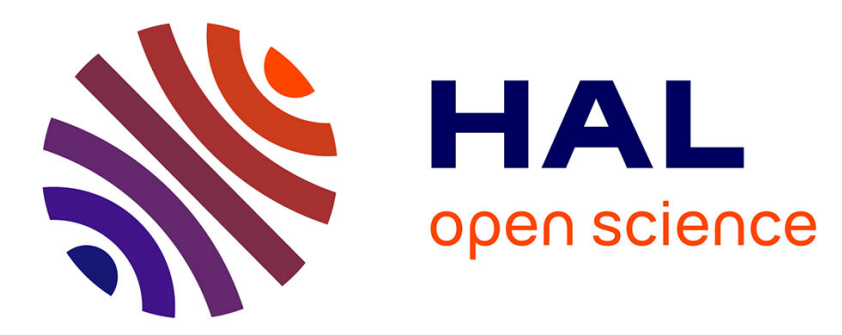

\title{
The Effect of Coercive Power on Supply Chain Inventory Replenishment Decisions
}

\author{
Ramesh Das Guru, Amin Kaboli, Rémy Glardon
}

\section{To cite this version:}

Ramesh Das Guru, Amin Kaboli, Rémy Glardon. The Effect of Coercive Power on Supply Chain Inventory Replenishment Decisions. IFIP International Conference on Advances in Production Management Systems (APMS), Sep 2014, Ajaccio, France. pp.230-237, 10.1007/978-3-662-44736-9_28 . hal-01387871

\section{HAL Id: hal-01387871 \\ https://hal.inria.fr/hal-01387871}

Submitted on 26 Oct 2016

HAL is a multi-disciplinary open access archive for the deposit and dissemination of scientific research documents, whether they are published or not. The documents may come from teaching and research institutions in France or abroad, or from public or private research centers.
L'archive ouverte pluridisciplinaire HAL, est destinée au dépôt et à la diffusion de documents scientifiques de niveau recherche, publiés ou non, émanant des établissements d'enseignement et de recherche français ou étrangers, des laboratoires publics ou privés. 


\title{
The Effect of Coercive Power on Supply Chain Inventory Replenishment Decisions
}

\author{
Ramesh Roshan Das Guru, Amin Kaboli and Rémy Glardon \\ Laboratory for Production Management and Processes \\ Swiss Federal Institute of Technology at Lausanne (EPFL) \\ CH-1015 Lausanne, Switzerland \\ ramesh.dasgurudepfl.ae, amin.kaboli@gmail.com, \\ remy.glardon@epfl.ch
}

\begin{abstract}
Supply chains often consist of stakeholders with different power levels collaborating with each other in order to meet customer demand. This imbalance of power along the supply chain is a critical factor that affects its short and long-term behavior, as well as its overall stability and efficiency. The role and the impacts of power in distribution channels have been explored quite extensively in Marketing, but far less so with regard to power in the context of supply chains. This paper explores the effect of power on supply chain functioning by focusing on a specific power type i.e. coercive power. More specifically, the impact of power and power awareness on inventory replenishment human decision-making is investigated. An experimental approach with unknown market demand and local information availability is implemented so as to provide a controlled environment for decision-making. Three different treatments are implemented in order to create situations of balanced power, imbalanced power without awareness and imbalanced power with awareness. Results show that power awareness does play a significant role in the way coercive power is exercised. In particular, a significant increase of the size and variability of order quantity and order time interval is observed in the case of imbalanced power with awareness.
\end{abstract}

Keywords: Coercive power, decentralized supply chain, inventory replenishment, power awareness, human decision-making 


\section{$1 \quad$ Background}

Power in supply chain is the ability of one firm (source) to influence the actions and intents of another firm (target) it deals with [Maloni and Benton, 2000]. Power in supply chain can be either balanced or imbalanced. Balanced power exists when stakeholders in the chain possess broadly similar levels of power in influencing each other's decisions, while imbalanced power exists when one or more partners (sources) are capable of manipulating decisions of the other partners (targets) because of their power position [Muthusamy and White, 2006]. The exercising of power in a supply chain can have positive, as well as negative effects on its overall performance. Some of these effects can be visible immediately but most of them emerge out over a longer period of time [Hanf and Belaya, 2009].

Amongst the various power types defined by French and Raven (1959), coercive power is referred to as the ability of a source to punish a target in case of failures. Based on studies done by Yeung et al. (2009), coercive power tends to improve supplier integrations, with or without the presence of trust, which is again a positive outcome for the overall supply chain. These authors argue that the exercise of power ends up assuring the congruence in goals and activities of different associated partners, particularly in the absence of a well-specified cooperation agreement.

Most of the time, partners in supply chains are not completely aware of the broad scope of their power dimensions and therefore end up not actively managing their own power bases [Cordon and Vollmann, 2005]. Understanding and awareness of power structure is a crucial factor in management of supply chains and selection of the appropriate reactive or proactive strategy, since it can be easily connected to the dominance and interdependence of partners in the chain [Cox et al., 2004]. Thus awareness of power is central since exercising available power is very much dependent on its awareness.

Unlike other attributes of supply chain partnerships, power and its impact cannot be readily measured. Power, as stated earlier, is a mixture of complex social, economic and even psychological factors.

Despite the existence of numerous contributions investigating the role of factors such as trust, commitment and shared meaning, the literature suggests that there is a lack of empirical research examining the effect of power in supply chains. Most of the earlier research works on this topic were done using surveys, interviews and analysis of field data [Cox, 1999; Maloni and Benton, 2000: Yeung et al., 2009]. These empirical studies are generally case based, hence restricting the opportunity to develop general conclusions. This scarcity of empirical research examining the impacts of power exercised by partners in a supply chain is the central motivation for this work. Accordingly, the main goal of this study is to investigate the impact of coercive power on inventory replenishment decision. To this end, a controlled experiment is implemented, using a participatory simulation platform. It allows simulating supply chains with balanced and imbalanced power regimes among different players and analyzing the resulting impact on inventory replenishment decisions. The experiment and further analysis aim at answering the main question of this study: How does imbalanced 
coercive power and its awareness impact on the replenishment decision-making in supply chains?

The next section provides the methodology and experimental approach. Section 3 provides the results and statistical analysis of the experiment. Finally, a discussion and conclusion are given in Section 4.

\section{Methodology}

To understand the dynamics and complexity of inventory replenishment decisionmaking, supply chain simulation has been shown to be an appropriate research tool [Croson and Donohue 2002]. In particular, simulation helps creating a stable and controlled environment that allows reliable observations of the decision maker's behavior over time. In this study, a participatory simulation platform developed at Université Laval, Québec, Canada, called XBG-platform, is used for the experiments with human decision makers [Montreuil et al. 2008]. The XBG-platform mimics the dynamics of inventory replenishment in a decentralized, linear, four echelon supply chain. Order size and order time can be freely chosen; thus any order placement implies a twofold decision about time and quantity.

In Fig. 1, filled rectangles represent echelons with human participants, and empty rectangles represent echelons with computer agents. Human participants, thereafter subjects, played the role of the wholesaler and computer agents played factory, distributor, retailer and market roles. The main reason to use an experimental set-up with one single subject is to avoid interaction of human decision-making between echelons. None of the subjects were made aware of the fact that the computer simulated other echelons.

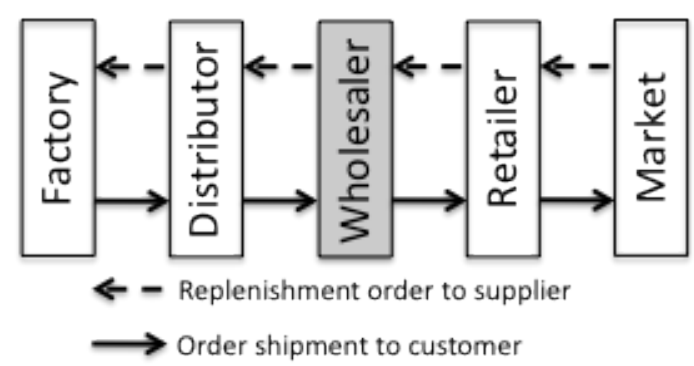

Fig. 1. Structure of the Supply Chain used in XBG simulation.

The market demand is stable and follows a normal distribution with a mean of 3000 units/day and a standard deviation of 500 units/day, truncated at zero. This daily demand is randomly split into two orders per day. The demand information is unknown to the subjects.

This experiment is divided into three settings based on the power and awareness levels of the subjects. The imbalance of power between the echelons is achieved by varying the level of backorder costs between them. The awareness of power is incorporated with the introduction of contracts, which the player must sign before starting 
the game. The contract contains information about the business environment and commercial conditions, which makes the player aware of the power he/she holds over his/her supplier. The objective of the subject is to maximize his/her benefit, which is rewarded with a performance-based payment up to $60 \mathrm{CHF}$. Three different treatments are used to generate the required levels of power and power awareness.

- Treatment 1: Balanced power. Backorder costs are identical for all echelons, therefore leading to power equilibrium between them.

- Treatment 2: Imbalanced power without awareness. The backorder cost to be paid by the distributor to the wholesaler (subject) is doubled, but the contract signed by the subject does not mention this fact. All other relations within the supply chain are in power equilibrium.

- Treatment 3: Imbalanced power with awareness. The backorder cost to be paid by the distributor to the wholesaler (subject) is doubled and the contract signed by the subject explicitly mentions this fact. All other relations within the supply chain are in power equilibrium.

The supply chain parameters considered in the experiments are defined in Table 1.

Table 1. Summary of the variables

\begin{tabular}{|lc|lc|}
\hline Variable & Symbol & Variable & Symbol \\
\hline Ordered quantity & OQ & Purchasing cost & PC \\
Ordering time interval & OT & Backorder cost & BC \\
On-hand inventory & OI & Inventory carrying cost & IC \\
Supply line & SL & Operating cost & OC \\
& & Total cost & TC \\
\hline
\end{tabular}

Twenty-four undergraduate and graduate students representing 15 nationalities from EPFL's engineering and business majors participated in the experiment. The subjects consisted of $21 \%$ women and $79 \%$ men, with $29 \%$ of students in their Bachelor and $71 \%$ in their Master. To analyze the evolution of decision-making in the span of four months of game duration, the obtained data are divided bimonthly in 8 rounds. Consequently the database consists of a total of 24 subjects $\mathrm{x} 8$ rounds $=192$ results; i.e. 64 observations per treatment.

\section{$3 \quad$ Results and Statistical Analysis}

The obtained experimental results are analyzed over the whole game, separately for each treatment T1 (balanced power), T2 (power without awareness) and T3 power with awareness). The values reported for each treatment group (T1 to T3) represent the average of all the subjects in that particular setting throughout the duration of four months of game (64 observations). The statistical significance of all observations is checked using the Mann Whitney test (criterion $\mathrm{p}<0.05$ ). These aggregated experi- 
mental results are presented in the next four sub-sections as follows: 3.1 Replenishment decision indicators, 3.2 Inventory indicators and 3.3 Cost components.

\subsection{Replenishment decision indicators}

As described earlier, the replenishment decision in this study involves two indictors, namely ordered quantity (OQ) and order time interval (OT). The results presented in Fig. 2 indicate no significant differences between treatments $\mathrm{T} 1$ and $\mathrm{T} 2$ but a very significant increase in the magnitude and variability of both OQ and OT in case of treatment T3, i.e. in case of power awareness.

The above observations are statistically confirmed by the Mann Whitney test scores, as indicated in Fig. 2.
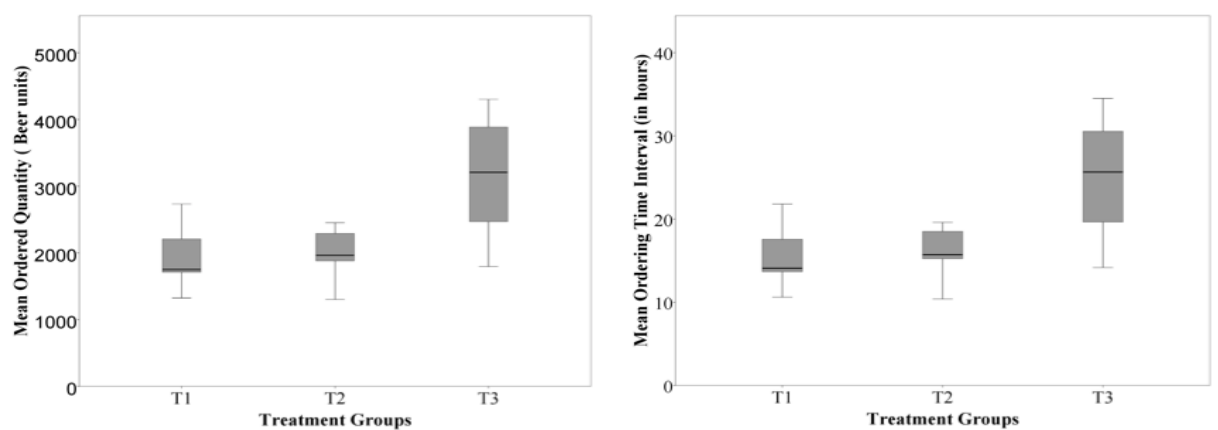

\begin{tabular}{|c|c|c|c|c|}
\hline \multicolumn{5}{|c|}{ Mann-Whitney test scores } \\
\hline $\begin{array}{c}\text { Settings } \\
\text { compared }\end{array}$ & Z score & p value & Z score & $p$ value \\
\hline & \multicolumn{2}{|c|}{$\mathrm{OQ}$} & \multicolumn{2}{|c|}{ OT } \\
\hline$T 1$ versus $T 2$ & -0.365 & 0.715 & -0.416 & 0.677 \\
\hline $\mathrm{T} 1$ versus $\mathrm{T} 3$ & -2.333 & 0.020 & -2.123 & 0.020 \\
\hline$T 2$ versus $T 3$ & -2.109 & 0.034 & -2.239 & 0.025 \\
\hline
\end{tabular}

Fig. 2. Mean OQ and OT for treatments T1, T2 and T3.

\subsection{Inventory Indicators}

Two indicators are considered, the on-hand inventory (OI) and the supply line (SL). Fig. 3 shows no significant differences between treatments $\mathrm{T} 1$ and T2 but a significant increase in the magnitude and variability of OI in case of treatment T3, i.e. in case of power awareness. With regard to SL, an increase in its variability, but not in its magnitude is noticed for treatment $\mathrm{T} 3$.

The above observations on OI and SL are confirmed by the Mann Whitney test scores provided in Fig. 3. For OI, a significant difference is confirmed between treatments T2 and T3. For all other comparisons, including T1/T3, no statistical significance is found (criterion $\mathrm{p}<0.05$ ).

With regard to SL, the statistical tests confirm also a significant difference between $\mathrm{T} 2$ and T3. Although there is an observable difference between T1 and T3, its significance is not confirmed by the Mann Whitney test for the selected criterion of $p<0.05$. 

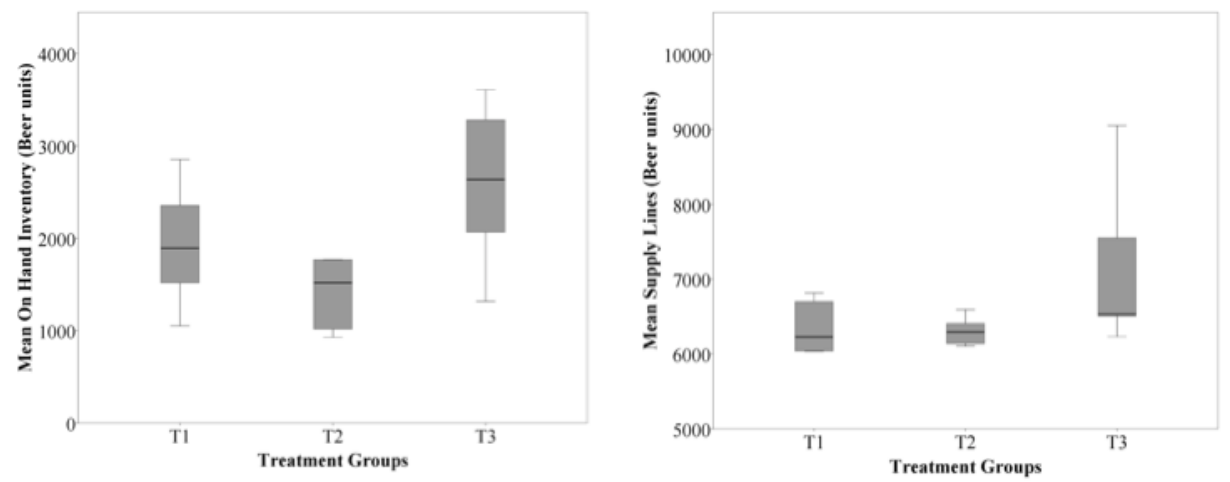

\begin{tabular}{|c|c|c|c|c|}
\hline \multicolumn{5}{|c|}{ Mann-Whitney test scores } \\
\hline $\begin{array}{c}\text { Settings } \\
\text { compared }\end{array}$ & Z score & p value & Z score & p value \\
\hline & \multicolumn{2}{|c|}{ OI } & \multicolumn{2}{|c|}{$\mathrm{SL}$} \\
\hline$T 1$ versus $T 2$ & -1.461 & 0.144 & 0.000 & 1.000 \\
\hline$T 1$ versus $T 3$ & -1.533 & 0.125 & -1.667 & 0.096 \\
\hline $\mathrm{T} 2$ versus $\mathrm{T} 3$ & -2.357 & 0.018 & -2.357 & 0.018 \\
\hline
\end{tabular}

Fig. 3. Mean OI and SL for treatments T1, T2 and T3.

\subsection{Cost Components}

As defined above, the considered cost components are:

- The operating cost (OC), defined as the sum of the backorder (BC) and inventory carrying (IC) costs $(O C=B C+I C)$,

- The total cost (TC), defined as the sum of the operating (OC) and purchasing (PC) costs $(T C=O C+P C=B C+I C+P C)$.

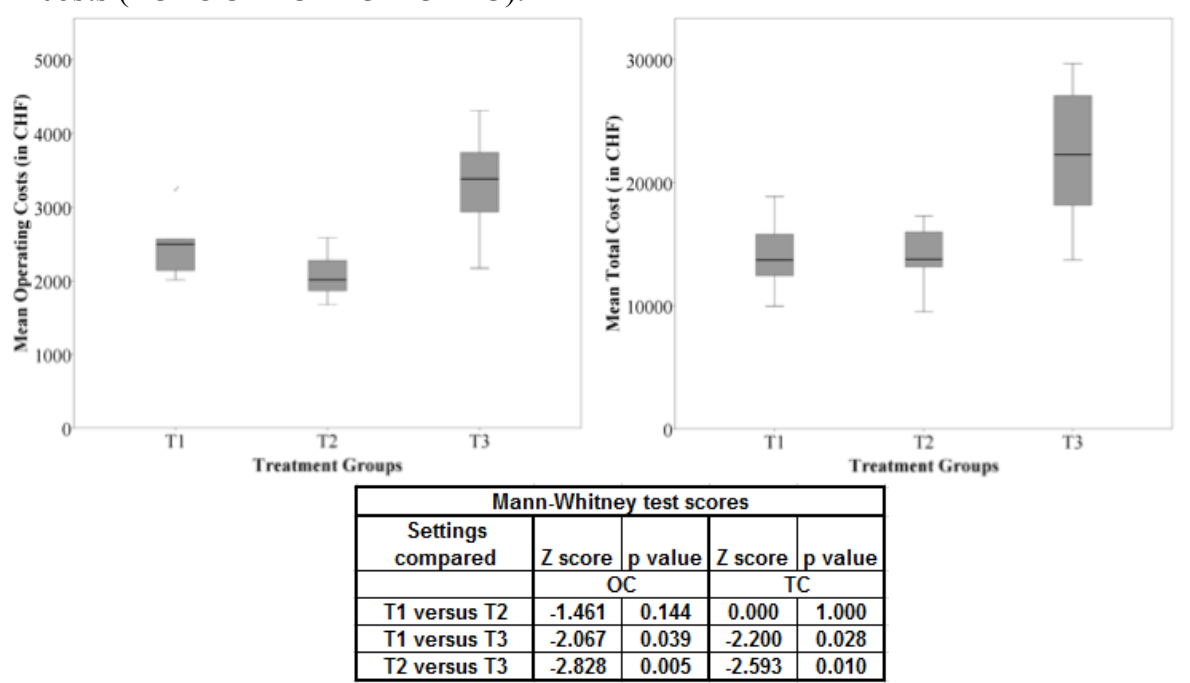

Fig. 4. Mean OC and TC for treatments T1, T2 and T3. 
Both OC and TC are considered in the analysis of the experimental results and presented in Fig. 4. They indicate no significant differences between treatments $\mathrm{T} 1$ and $\mathrm{T} 2$, but a significant increase in the magnitude and variability of both $\mathrm{OC}$ and TC in case of treatment T3, i.e. in case of power awareness.

The statistical analysis by Mann Whitney test scores confirms the results described above (see Fig. 4). For both OC and TC, the differences between treatment T3 versus treatments $\mathrm{T} 1$ and $\mathrm{T} 2$ are shown to be significant.

\section{Discussions and Conclusion}

It is important to recall that the use of a controlled and reproducible experimental environment assures that all observations are strictly due to changes in the human replenishment decision process. Thus, the statistical analysis of the experimental data in the three different settings T1, T2 and T3, with varying power and awareness levels, leads to the following main observations.

- Observation 1: Holding power without having its complete awareness creates no significant change in ordering behavior, inventory levels and costs compared to a power equilibrium situation (T2 versus $\mathrm{T} 1$ ).

- Observation 2: Holding power and being completely aware about it leads to a significant impact in inventory replenishment decision, inventory levels and costs when compared to a power equilibrium situation (T3 versus T1).

In particular, the following significant impacts are observed: a) Ordered quantity and Ordering time interval are increased, b) Inventory levels are increased c) Cost components are increased.

As T1 (balanced power) and T2 (imbalanced power without awareness) lead to very similar results, the following discussion is limited to the comparison of two situations: T3 (imbalanced power with awareness) versus T1 (balanced power).

The significant difference observed in the ordering behavior (increased ordered quantity (OQ) and increased ordering time interval (OT) can be considered as being at the origin of the other observations. In particular, the higher inventory level can reasonably be attributed to the larger order quantity. It is interesting to notice that the supply line is not significantly changed, even though the purchase satisfaction is reduced. These suggest that the increased order quantity reduces the reactivity of the supplier (as partial delivery is not allowed) but does not significantly hamper its ability to ship; i.e. increase its backlog..

A first analysis of the global supply chain performances has shown that a significant drop of the total supply chain profit occurs in case of exercising coercive power (T3). This is an indication that coercive power in supply chain has a negative effect on its integration and efficiency.

Through the use of a controlled experimental set-up it has thus been possible to observe that coercive power in supply chains significantly impacts its behavior and performances. It can in particular be concluded that, in a controlled and stable environment, exercising coercive power within a supply chain tends to reduce its performance. The Supply Chain costs are increased and the overall profit reduced, but the 
final customer satisfaction is not so much affected. A first analysis of the intra-supply chain results indicates also that the reduced total Supply Chain profit is shared in a less even way, which is detrimental to the partner under power dependence. This may ultimately lead to additional intra-chain dissatisfactions, and therefore to further degradation of the Supply Chain performances with time.

Real Supply chains are of course significantly more complex and less stable than the well-controlled experimental environment used in this study. Nevertheless, the obtained results being strictly due to human decision-making, it can be expected that similar tendencies would be observed in practice. Consequently, it means that a strong imbalance of power in a decentralized Supply Chain is adverse.

\section{Acknowledgement}

The authors wish to thank Prof. Benoit Montreuil and his research team at Université Laval for providing the participatory simulation platform XBG and for efficiently supporting its use and maintenance. Thanks are also due to Mr. Marc Matthey for his technical support and to Mrs. Ioanna Paniara for helping with the preparation of this manuscript.

\section{References}

1.Cordón, C., Vollmann, T. E. (2005). Supply Chain Dyads: Developing the Chain Linkages. International Institute for Management Development (IMD)

2.Cox, A. (1999). Power, value and supply chain management. Supply Chain Management: An International Journal, 4(4), 167-175.

3.Cox, A., Watson, G., Lonsdale, C., \& Sanderson, J. (2004). Managing appropriately in power regimes: relationship and performance management in 12 supply chain cases. Supply Chain Management: An International Journal, 9(5), 357-371.

4.Croson, R., \& Donohue, K. (2002). Experimental economics and supply-chain management. Interfaces, 32(5), 74-82.

5.French, J. R., \& Raven, B. H. (1959). The Bases of Social Power, [w:] The Studies on Social Power, D. Cartwright (red.). Ann Arbor.

6.Hanf, J., \& Belaya (2009) V. THE "DARK" AND THE "BRIGHT" SIDES OF POWER IN SUPPLY CHAIN NETWORKS. Schriften der Gesellschaft für Wirtschafts-und Sozialwissenschaften des Landbaus eV Band 44 (2009) 279.

7.Maloni, M., \& Benton, W. C. (2000). Power influences in the supply chain. Journal of Business Logistics, 21(1), 49-73

8.Montreuil B., Brotherton E., Glardon R., Yoo M-J., Elamiri Y., Borter A.-S., Morneau A., Naciri S. and Jermann P,(2008) Experiences in Using XBeerGame Virtual Gaming for Learning Supply Chain Management, 2nd European Conference on Games Based Learning, 16-17 October, 2008. Univesitat Oberta de Catalunya, Spain

9.Muthusamy, S. K., \& White, M. A. (2006). Does power sharing matter? The role of power and influence in alliance performance. Journal of Business Research, 59(7), 811-819.

10.Yeung, J. H. Y., Selen, W., Zhang, M., \& Huo, B. (2009). The effects of trust and coercive power on supplier integration. International Journal of Production Economics, 120(1), 6678. 